Please cite the published version of this paper from British Journal for the History of Philosophy (https://doi.org/10.1080/09608788.2020.1807908).

After submitting the final version of the paper, I learned about the article 'The concept horse is a concept' by Ansten Klev, published in the Review of Symbolic Logic in 2018. Had I known of this article earlier, I should have referred to it. For instance, Klev's observation that the truth of ' $x$ is a function' is a presupposition for the well-formedness of any second-order formula supposedly expressing that very truth, is echoed in my own arguments (although we move in quite different directions).

\title{
Why did Frege reject the theory of types?
}

\begin{abstract}
I investigate why Frege rejected the theory of types, as Russell presented it to him in their correspondence. Frege claims that it commits one to violations of the law of excluded middle, but this complaint seems to rest on a dogmatic refusal to take Russell's proposal seriously on its own terms. What is at stake is not so much the truth of a law of logic, but the structure of the hierarchy of the logical categories, something Frege seems to neglect. To come to a better understanding of Frege's response, I investigate his conception of the nature of the logical categories, and how it differs from Russell's. I argue that, for Frege, our grasp of the logical categories cannot be severed from our grasp of the Begriffsschrift notation itself. Russell, on the other hand, attaches no such importance to notation. From Frege's point of view, Russell has not succeeded in presenting an alternative conception of the logical hierarchy, since such a conception must go together with the development of a notation. Moreover, Frege has good reasons to think that Russell's proposal does not admit of a suitable notation.
\end{abstract}

Keywords: Frege, Russell, theory of types, logical categories, Begriffsschrift

\section{Introduction}


As is well known, Russell discovered a paradox plaguing any notion of 'set' governed by a naïve comprehension schema, a paradox that infected Frege's logical system from his Grundgesetze. When Russell brought it to Frege's attention, Frege replied that this left him deeply disturbed (bestürzt) (PMC, 132). As is also well known, Russell proceeded to develop his theory of types - which came to fruition in his and Whitehead's Principia Mathematica - as a way to circumvent the paradox.

What has received less attention, however, is the fact that - when Russell presented an incipient version of it in their correspondence (PMC, 144-145) - Frege himself rejected the theory of types as an adequate solution to the paradox. This raises a deceptively simple question: why, given that he must have been desperate for a solution, did Frege reject the theory of types?

To my mind, this question deserves a more thorough treatment than it has been given so far, for a couple of related reasons. First, answering it is not as straightforward as one might think. Simply appealing to Frege's conception of the absolute generality of logic, for instance, is unsatisfactory. To fully understand why Frege rejected the theory of types, we must delve deeper into Frege's philosophy of logic, his conception of the logical categories, and the status that he accorded to the Begriffsschrift qua logically perspicuous notation. Second, such an investigation makes salient some of the fundamental differences between Frege and Russell. Where they have historically been cast as proponents of a more or less homogenous philosophical program - usually under the guise of 'logicism'1 - scholars have increasingly come to recognize that there are profound differences between them, e.g. (Klement, 2004) (Kremer, 2006). Understanding Frege's rejection of the theory of types further contributes to this deepened awareness of the differences between Frege and Russell. Third, the correspondence between Frege and Russell is itself a

\footnotetext{
${ }^{1}$ See (Kremer, 2006, 163) for an overview of some such accounts.
} 
document of considerable philosophical interest that deserves to be studied in more detail than it has been so far. In Russell, Frege found one of his most capable interlocutors. Notwithstanding their differences, it was clear that Russell intended to take Frege's work seriously in a way that most of his contemporaries didn't. Because of this, their correspondence reaches and maintains a singular philosophical depth.

In this paper, I approach the issue from Frege's side. My main question is: what principled reasons were available to Frege for rejecting the theory of types, as Russell proposed it to him? My discussions of Russell are subservient to this question, and are not meant to give a comprehensive account of Russell's side of the debate, which would require another paper. I am therefore also not claiming that Frege's position is superior. I only want to get as clear about it as I can. As we will see, this involves certain issues that have come to animate contemporary Frege scholarship, especially in relation to so-called resolute readings of the Tractatus. ${ }^{2}$

\section{Part I: Russell's proposal and Frege's reply}

In this first part, I present the incipient version of the theory of types that Russell proposed to Frege as a solution to the paradox, ${ }^{3}$. The aim is to show that there is something prima facie

\footnotetext{
${ }^{2}$ (Diamond, 1991) and (Conant, 2002) are canonical examples. Below, I briefly indicate what I take to be the upshot of my discussion for our understanding of the Tractatus.

${ }^{3}$ In Frege's system, the paradox runs as follows: consider the concept 'extension of a concept that does not fall under that concept'. Then the extension of this concept falls under it if and only if it does not. Formally, it involves ranges-of-values, Frege's analogue of classes or sets. The range-of-values of a function $F(\xi)$ is denoted ' $\dot{\varepsilon} F(\varepsilon)$ '. Two functions have the same range-of-values if and only if they have the same value for all objects (this is Frege's Basic Law V) (GGA, I, §20). Extensions are rangesof-values of concepts. Concepts are functions that map any object either to the True or the False. Now let ' $\psi(\xi)$ ' be a concept such that $(\forall \varphi)(\psi(\grave{\varepsilon} \varphi(\varepsilon)) \equiv \neg \varphi(\grave{\varepsilon} \varphi(\varepsilon)))$. Then $\psi(\grave{\varepsilon} \psi(\varepsilon)) \equiv \neg \psi(\grave{\varepsilon} \psi(\varepsilon))$.
} 
puzzling about Frege's response to that proposal: Frege seems to fail to take Russell's proposal seriously on its own terms. This sets the task for the remainder of the paper: to investigate whether Frege had more principled reasons to reject Russell's proposal.

Russell's incipient version of the theory of types runs as follows:

The contradiction could be resolved with the help of the assumption that ranges of values are not objects of the ordinary kind; i.e. that $\varphi(x)$ needs to be completed (except in special circumstances) either by an object or by a range of values of objects or by a range of values of ranges of values, etc. This theory is analogous to your theory about functions of the first, second, etc. levels. In $x \cap u^{4}$ it would be necessary that $u$ was a range of values of objects of the same degree as $x ; x \cap x$ would therefore be nonsense [Unsinn]. [...] For every function $\varphi(x)$ there would accordingly be not only a range of values but also a range of those values for which $\varphi(x)$ is decidable, or for which it has a sense [Sinn]. The striving for generality would accordingly be a mistake; i.e. $(\forall x)(\varphi(x))$ does not mean the assertion of $\varphi(x)$ for all values of $x$, but the assertion of all propositions of the form $\varphi(x)$ (PMC, 144-145).

The core idea is this: objects are segmented into logical types, and argument-places of first-level function expressions are typed, i.e. only admit proper names of objects of a single type. This is the proposal to which we shall be investigating Frege's response in detail. It must be noted that Russell himself quickly abandoned it. The later versions of the theory of types no longer commit Russell to ontological types. ${ }^{5}$

\section{Violations of the law of excluded middle}

\footnotetext{
${ }^{4}$ Frege's version of ' $x \in u$ '.

${ }^{5}$ See (Landini, 1998, 140) (Klement, 2004, 13). There is an important philosophical reason for this, which we will encounter below.
} 
Frege replies to Russell's proposal both in the correspondence and in the Appendix to the second volume of the Grundgesetze. A good starting point is Frege's claim that the theory of types commits one to violations of the law of excluded middle. He writes:

A class would not then be an object in the full sense of the word, but - so to speak - an improper object for which the law of excluded middle did not hold because there would be predicates that could be neither truly affirmed nor truly denied of it (PMC, 145). ${ }^{6}$

In Frege's mind, the idea of typed objects is inherently tied to giving up the law of excluded middle. Earlier in the correspondence, in response to what could be seen as an incipient version of Russell's vicious circle principle, Frege wrote:

It seems that you want to prohibit formulas like ' $\varphi(\grave{\varepsilon} \varphi(\varepsilon))$ ' in order to avoid the contradiction. But if you admit a sign for the extension of a concept (a class) as a meaningful proper name and hence recognize a class as an object, then the class itself must either fall under the concept or not; tertium non datur. If you recognize the class of square roots of 2 , then you cannot evade the question whether this class is a square root of 2 (PMC, 135).

The proposition 'the class of square roots of 2 is a square root of 2' can be expressed as follows: ' $\left(\grave{\varepsilon}\left(\varepsilon^{2}=2\right)\right)^{2}=2$ '. From Frege's logical point of view, this expresses a thought which is either true or false. The idea that the theory of types violates the law of excluded middle is the idea that it commits one to claiming, of such thoughts, that they are neither true nor false. ${ }^{7}$

\footnotetext{
${ }^{6}$ See also (GGA, II, 254). Note that Frege is focusing on the law of excluded middle as entailing that any predicate can be affirmed truly or falsely of any object. I shall do so as well.

${ }^{7}$ It should be noted that Frege himself seems to accept the possibility of expressing thoughts that are neither true nor false, if a component of the sentence has sense but lacks meaning (CP, 162) (PW, 194, 232). It is clear, however, that this sort of case is not at issue in his discussion with Russell, where the meaningfulness of all components is presupposed.
} 
From the logical point of view of the theory of types, however, this is not a correct description of the situation. It is not that there is a thought which is neither true nor false, a logically defective thought, as it were. Rather, the claim is that this sentence expresses no thought at all, that it is nonsensical, as Russell explicitly says. There is no such thing as subsuming the extension of a concept under that very concept.

This point can be made more salient by looking at Frege's own logical category distinctions. According to Frege, there is a sharp distinction between objects and concepts (or functions) ${ }^{8}$, so that, unlike objects, first-level concepts cannot be subsumed under other first-level concepts: "Concepts cannot stand in the same relations as objects. It would not be false, but impossible to think of them as doing so" (PW, 120). See also (CP, 189) (PW, 177-178, 182). Frege's preferred way of phrasing the distinction is by saying that objects are complete while concepts and functions are unsaturated and thereby require completion (CP, 193-194) (GGA, I, §1) (PW, 119-120). The unsaturatedness of concepts is indicated by an argument-place in their designations marked by a Greek letter: ' $\xi$ is a horse' or, in Begriffsschrift, ' $\varphi(\xi)$ '. Such designations can be completed to form a sentence by inserting a proper name into the argument-place: 'Seabiscuit is a horse' or ' $\varphi(a)$ '. Now imagine someone claiming that Frege's sharp distinction between concept and object falsifies the law of excluded middle, because it does not allow one to predicate a concept of itself. Given a concept $\varphi$, the objection goes, Frege's logic does not recognize ' $\varphi(\varphi)$ ' as being either true or false. Frege would reply that this rests on a neglect of the sharp distinction between concept and object. In his presentation of the paradox to Frege, Russell himself used precisely the idea of

\footnotetext{
${ }^{8}$ Before Funktion und Begriff, Frege did not yet conceive of concepts as functions, so that he talks about the distinction between concept and object. After that essay, that distinction is transformed into a corollary of the distinction between function and object.
} 
predicating a concept of itself, and Frege chided him for it: "A predicate is as a rule a first-level function which requires an object as argument and which cannot therefore have itself as argument" (PMC, 132). Insofar as ' $\varphi(\varphi)$ ' expresses a thought, it must consist in the subsumption of an object under a concept, so that we need to analyze it as consisting of a concept expression ' $\varphi(\xi)$ ' and a proper name ' $\varphi$ ' which completes it. These contribute to the expression of the thought in logically different ways. This is exactly what Frege does in his own rendition of the paradox: the confused idea of a concept that is predicated of itself is replaced by that of a concept that is predicated of its own extension: ' $\varphi(\dot{\varepsilon} \varphi(\varepsilon))$, ${ }^{9}$ This expresses a logically perfectly definite thought that is either true or false. For Frege, it is the only proper way to express the paradox. Either the phrase 'asserting $\varphi(\xi)$ of itself' is understood in this way, or it must be regarded as nonsensical. In neither case is there a violation of the law of excluded middle, i.e. a thought that is neither true nor false. ${ }^{10}$

Back to Russell. Taking a cue from Frege, Russell could reply that Frege's claim that ' $\left(\grave{\varepsilon}\left(\varepsilon^{2}=2\right)\right)^{2}=2$ ' expresses a thought rests on a neglect of the type-distinctions between objects. From Russell's point of view, Frege has not succeeded in expressing a thought, so that there is no violation of the law of excluded middle. Similarly, no sense can be made of Frege's notion of 'improper object' from the logical point of view of the theory of types. The idea is that of an object $a$ of which some predicates can be neither affirmed nor denied, which one could try to express as

\footnotetext{
${ }^{9}$ See (GGA, II, 256ff.) for Frege's formal investigation of the paradox.

${ }^{10}$ An anonymous referee put to me the question whether there can be, for Frege, a thought that is both true and false, for instance one generated by Russell's paradox? No. Frege would say that the paradox shows - not that we have thoughts that are both true and false - but that no thought is expressed. There is no such thing, for Frege, as a 'contradictory thought'. Indeed, in Frege's framework, this would amount to a proper name that simultaneously refers to two objects (the True and the False), which is an absurdity.
} 
follows: $(\exists \varphi)(\neg \varphi(a) \wedge \neg \neg \varphi(a))$. Here, we are quantifying over first-level functions. Such quantification, however, is itself restricted to functions of a fixed type. There are two possibilities. Either we are quantifying over the type of functions that take arguments of the same type as $a$. In that case, ' $(\exists \varphi)(\neg \varphi(a) \wedge \neg \neg \varphi(a))$ ' is simply false. Or, we purport to be quantifying over functions such that $a$ is not of the right type. But then ' $\varphi(a)$ ', insofar as it purports to designate the result of applying such a function to $a$, is nonsensical, so that ' $(\exists \varphi)(\neg \varphi(a) \wedge \neg \neg \varphi(a))$ ' is nonsensical as well. Again, there is no violation of the law of excluded middle.

\section{The absolute generality of logic}

According to Frege, laws of logic apply without restriction to all objects, all first-level functions, etc., as has been stressed by (Van Heijenoort, 1967, 325) (Ricketts, 1986, 76) (Goldfarb, 2001, 27-28) (Taschek, 2008, 380-381) (Weiner, 2010, 34-35; 49-50; 56ff.). The law of excluded middle, as Frege understands it, must pertain to the subsumption of any object under any concept. We can see this concern with absolute generality - in this case the absolute generality of the law of identity - motivating the following consideration:

There would, however, be some functions which could have both proper and improper objects as arguments. At least the relation of equality (identity) would be of this kind. One might try to avoid this by assuming a special kind of equality for improper objects. But that is surely ruled out. Identity is a relation given in so determinate a way that it is inconceivable that different kinds of it could occur (GGA, II, 254).

A similar statement is found at (PMC, 145). This yields another objection to the theory of types, namely that it undermines the absolute generality of logic by restricting logical generality to a specific type of objects or functions. Indeed, Russell himself states that, from the vantage point of 
the theory of types, "the striving for generality would accordingly be a mistake" (PMC, 145).

This remark is somewhat infelicitous, since it can be read as a confirmation by Russell that he is relinquishing the absolute generality of logic, which must have been disconcerting to Frege. Nevertheless, from the logical point of view of the theory of types, there is no genuine denial of the absolute generality of logic. Rather, it is Frege's conception of that absolute generality that is regarded as logically confused, because it rests on a neglect of type-distinctions. For Frege, there is a univocal notion of 'object', which subsumes anything that can complete a first-level function. From the logical point of view of the theory of types, no sense can be made of such a notion of 'object'.

Once again, we can make this point more salient by imagining someone raising a similar objection against Frege. For instance, the earlier Russell of Principles of Mathematics takes there to be one all-encompassing logical category of terms that subsumes both functions and objects (PoM, §§47-48). From this vantage point, early Russell could say that Frege violates the absolute generality of logic, since he refuses to quantify over terms, i.e. over both functions and objects. Frege would, of course, reply that logical generality is itself constrained by the sharp distinction between functions and objects. For Frege, a generality that encompasses both functions and objects is a logically confused idea. Moving back to Russell's proposal from the correspondence, we see that he can reply to Frege that logical generality is also constrained by type-distinctions between objects, so that a Fregean absolute generality that encompasses all objects itself turns out to be a confused idea. In the same way that Frege would not accept the charge that he is restricting logical generality with his radical distinction between concept and object, Russell need not accept Frege's charge that he is restricting logical generality with his type-distinctions between objects. 


\section{The structure of the hierarchy of the logical categories}

This makes more salient an aspect that threatens to be overlooked when one limits oneself to the concern with the law of excluded middle. What is at stake is not so much which laws of logic are true, but rather the structural framework wherein such laws are formulated, the structure of the hierarchy of the logical categories (henceforth: logical hierarchy) itself. ${ }^{11}$ Both Frege and Russell accept the law of excluded middle, law of identity, etc., but they differ as to the structure of the logical hierarchy wherein, we could say, such laws have their home. The problem with Frege's remarks about the law of excluded middle is precisely that there is no 'framework neutral' formulation of that law which can be applied both to Frege's Begriffsschrift $t^{12}$ and Russell's theory of types, so that we could say that Frege's logic is faithful to it whereas Russell's logic violates it. Rather, it is the logical hierarchy itself that determines what generality is possessed by a law of logic. Russell's proposal challenges Frege's conception of that hierarchy. Frege, however, invokes precisely that conception in assessing it, and thereby appears to fail to take Russell's proposal seriously on its own terms.

We should not be too quick, however, in chastising Frege as a dogmatist. What is true, is that neither of the above replies - as we have understood them so far - offer good reasons to reject Russell's proposal. This does not mean, however, that no more principled grounds were available to Frege. I said that Frege and Russell disagree about the structure of the logical hierarchy. But this

\footnotetext{
${ }^{11}$ This distinguishes the topic at hand from that of so-called 'logical aliens' - hypothetical thinkers who reject our laws of logic - as they appear in (GGA I, xvi). How we should view the relation between these issues - the status of laws of logic and the status of the logical hierarchy - is itself a difficult question to which I cannot do justice here.

${ }^{12}$ I use the term 'Begriffsschrift' to refer to Frege's mature formal system, not his early book.
} 
presupposes that there is prior agreement about the nature of the subject matter about which they disagree, i.e. about the nature of the logical categories themselves. It presupposes that they agree about what it is to disagree about the structure of the logical hierarchy. I wish to argue that they do not, and that there are good reasons, from Frege's point of view, to doubt whether Russell has succeeded in giving expression to such a disagreement to begin with.

\section{Part II: Frege vis-à-vis Russell on the logical categories}

The discussion of the paradox in the correspondence is intertwined with a discussion about the logical categories. Russell explicitly objects to Frege's sharp distinction between objects and functions: "If there can be something which is not an object, then this fact cannot be stated without contradiction; for in the statement, the something in question becomes an object" (PMC, 134). The idea is this: since ' $\xi$ is not an object' is a concept, whatever occupies its argument place will ipso facto be an object, so that we can never truly say, of anything, that it is not an object. But Frege's sharp distinction between objects and functions, Russell reasons, commits us to claiming of functions that they are not objects. Russell concludes that Frege's conception of the logical hierarchy cannot be coherently stated, so that it must be rejected. Because of such considerations, Russell adopted the principle that "every constituent of every proposition must, on pain of selfcontradiction, be capable of being made a logical subject” (PoM, §52), ${ }^{13}$ a principle he regarded as incompatible with Frege's views.

\footnotetext{
${ }^{13}$ As (Klement, 2004) forcefully argues, this is a commitment that pervaded Russell's philosophy before he encountered Wittgenstein. It is because of this commitment that Russell developed the theory of types in such a way that it is not committed to ontological types.
} 


\section{Positive ascriptions of logical categories}

In replying to Russell's objection, Frege starts by focusing on what we can call positive ascriptions of logical categories, of the form ' $\xi$ is an object' and ' $\xi$ is a function'. The former, Frege acknowledges, is true whatever is inserted in its argument place (PMC, 136). This entails that the latter is false whatever is inserted in its argument place, i.e. that we cannot truly state that something is a function. Frege, however, sees natural language as the culprit. The problem is that natural language does not distinguish between the argument places of the expressions ' $\xi$ is an object' and ' $\xi$ is a function', in that both present themselves as taking proper names. But this is a limitation of natural language, not of logic. As Frege puts it: "The concept of a function must be a second-level concept, whereas in language it always appears as a first-level concept" (PMC, 136). The solution is to adopt a Begriffsschrift that does make the necessary distinctions: "In a conceptual notation we can introduce a precise expression for what we mean when we call something a function [...], e.g.: ' $\varepsilon \varphi(\varepsilon)$ '. Accordingly, ' $\varepsilon(\varepsilon \cdot 3+4)$ ' would express precisely what is expressed imprecisely in the proposition ' $\xi \cdot 3+4$ is a function"” (PMC, 136). Note, importantly, that ' $\varepsilon \varphi(\varepsilon)$ ' is not the expression for ranges-of-values, which uses the reverse spiritus. It is a new Begriffsschrift term that, as far as I know, appears nowhere else in Frege's oeuvre. ${ }^{14}$ It designates a second-level concept that yields the True whichever function is put into its argument-place.

By introducing a second-level concept, Frege makes explicit how the structure of the Begriffsschrift notation accounts for the different levels of arguments in a way that natural language

\footnotetext{
${ }^{14}$ The notation resurfaces at (PMC, 161), but is there used differently.
} 
does not. The crucial notational device is that of argument-places (or empty places) ${ }^{15}$ to mark both the unsaturatedness of functions and the type of arguments that serve to complete them. For instance, only expressions for a first-level function with one argument fit into the argument place of ' $\varepsilon \varphi(\varepsilon)$ ', which is indicated by the whole functional expression ' $\varphi(\varepsilon)$ '. ${ }^{16}$ The Greek letter ' $\varepsilon$ ' has to be bound by the ' $\varepsilon$ ' because it is not itself an argument-place of ' $\varepsilon$ ' $\varphi(\varepsilon)$ '. ${ }^{17}$

Through its device of different types of argument-places, the Begriffsschrift allows us to distinguish between a first-level subsumption of an object under a first-level concept, as in ' $F(a)$ ', and a second-level subsumption of a first-level function under a second-level concept, as in ' $\varepsilon(\varepsilon \cdot 3+4)$ '. Indeed, the problem of becoming clear about the distinction between first-level statements about objects and second-level statements about concepts came to be recognized by Frege as one of the core issues to be resolved by the Begriffsschrift, and was thereby at the center of his attention throughout his whole oeuvre. ${ }^{18}$

\section{Negative ascriptions of logical categories}

${ }^{15}$ Frege uses both terms, although 'empty places' threatens to be confusing, because it sounds strange to say that there can be different kinds of empty places (more on this below). Frege is adamant that an expression for a function must be accompanied by suitable argument-places, e.g. (CP, 141) (GGA II, $\S 147$, footnote 2) (PW, 156). In the correspondence, he chastises Russell for using function letters without argument-places (PMC, 160-161). See also (CP, 291) (GGA I, §1) (PW, 228, 239, 272), and especially (GGA I, §§21ff.)

${ }^{16}$ This is what Frege calls an argument-place of the second kind (GGA, I, §23).

${ }^{17}$ Frege consistently uses this device of binding such components of functional argument-places, for instance in (GGA, I, §25).

${ }^{18}$ See also (Macbeth, 2005). Frege's criticism of Hilbert, for instance, centers on the difference between first-level and second-level concepts, e.g. (CP, 283, 307-308). For some other places where this difference is explicitly discussed, see (CP, 153) (GGA, I, §21ff.) (PW, 182). 
We should notice, however, that this does not fully deal with Russell's objection. Even if Frege has offered us a way to articulate positive ascriptions of functionhood to first-level functions of one argument, he has not offered us a way to articulate the kind of propositions that Russell advances, such as those of the form ' $\xi$ is not a function', which we can call negative ascriptions of logical categories. In fact, Frege himself admits this: "Just as in language we cannot properly speaking say of a function that it is not an object, so we cannot use language [dieser Bezeichnung] to say of an object, e.g. Jupiter, that it is not a function" (PMC, 136). Note that the translation is misleading: 'dieser Bezeichnung' refers not to language as such but to the specific second-level concept ' $\varepsilon ́(\varepsilon)$ ' (discussed above) that Frege introduced just before. Thus, Frege is quite explicit that ' $\dot{\varepsilon} \varphi(\varepsilon)$ ' cannot be used to make negative ascriptions of functionhood to objects. This is because proper names do not fit into its argument place, in the way just explained, as is evident to anyone who has mastered the Begriffsschrift.

This seems to leave Frege in an awkward position. Russell demanded a statement of the distinction between objects and functions. Because such a statement involves negative ascriptions of logical categories, Russell believed that it cannot be provided. Frege seems to attempt to meet Russell's demand by introducing his second-level concept 'ć $\varphi(\varepsilon)$ ', but in the same breath acknowledges that it is not up to the task. What is going on here?

To understand this, we need to become clearer about the status of the second-level concept ' $\varepsilon \varphi(\varepsilon)$ ' in Frege's argument. So far, I have presented it as a way to articulate positive ascriptions of functionhood. This brings us to conceive of ' $\varepsilon \varphi(\varepsilon)$ ' as something like a primitive term that refers to the logical category of first-level functions of one argument, albeit with the limitation that it only yields positive ascriptions. On such a conception, it is true that we cannot coherently say of an object that it is not a function, but at least we can coherently say of a function that it is a function. 
Frege himself repeatedly remarks that the logical categories are primitive (CP, 147, 182-183, 281) (PMC, 142) (PW, 235, 271), which can lead one to think that it should be possible to introduce corresponding primitive Begriffsschrift terms that have the logical categories as their meaning, similar to the way in which, for instance, the identity-sign has the logically primitive notion of identity as its meaning.

I believe such a reading is inadequate, and misses the more subtle aspects of Frege's position. To start bringing this out, let us wonder about Frege's claim that we cannot coherently say of a function that it is not an object. We could introduce another primitive second-level concept ' $\pi \varphi(\pi)$ ' that is false whatever first-level function is put into its argument place, and claim that ' $\pi(\pi \cdot 3+4)$ ' expresses precisely what is expressed imprecisely when we say (falsely) ' $\xi 3+4$ is an object', so that ' $\neg \dot{\pi}(\pi \cdot 3+4)$ ' truly denies that this function is an object. The problem with this proposal, however, is that we want ' $\pi(\pi \cdot 3+4)$ ' to deny exactly what we affirm of an object like the number 4 when we say that 4 is an object. Otherwise, we are not really saying of a function that it is not an object, i.e. that it is not what 4 is. But ' $\pi(\pi \cdot 3+4)$ ' cannot fulfil this role, because ' $\xi$ is an object' and ' $\pi \varphi(\pi)$ ' are of different levels, and therefore cannot share their meaning. Similarly, ' $\xi$ is not a function' and ' $c ́ \varphi(\varepsilon)$ ' are of different levels, so we cannot use the former to deny what is affirmed with the latter.

The fact that an artificially introduced expression such as ' $\pi \varphi(\pi)$ ' cannot provide us with negative ascriptions of objecthood, should lead us to scrutinize the idea that the equally artificially introduced ' $\varepsilon \varphi(\varepsilon)$ ' does provide us with positive ascriptions of functionhood, i.e. that it has as its meaning the logical category of first-level functions of one argument. It is true that ' $\varepsilon \varphi(\varepsilon)$ ' is true of all such functions. This is the connection that exists between ' $\varepsilon \varphi(\varepsilon)$ ' and that logical category. It is this connection that Frege has in mind when he says that the notion of 'function' should be 
second-level rather than first-level, and that ' $\varepsilon \varphi(\varepsilon)$ ' is a precise expression for what we want to say (was man meint $)^{19}$ when we call something a function (PMC, 136). This connection, however, is insufficient to account for Frege's own use of logical category terms, which usually concerns contrastive statements that rely on negative ascriptions, as in the following passage:

Now just as functions are fundamentally different from objects, so also functions whose arguments are and must be functions are fundamentally different from functions whose arguments are objects and cannot be anything else $(\mathrm{CP}, 153)$.

Even when Frege uses the logical category terms positively, that use is inherently tied to the concomitant negative ascriptions that his conception of the logical hierarchy commits him to. Saying that Socrates is an object would be useless, for Frege, if it could not in the same breath be added that he is thereby not a concept. ${ }^{20}$ And this contrastive use of logical category terms cannot be captured by a primitive Begriffsschrift term such as ' $\varepsilon \varphi(\varepsilon)$ '. ${ }^{21}$ There is no translation into Begriffsschrift of such contrastive statements.

The reason why ' $\varepsilon \varphi(\varepsilon)$ ' is true of all first-level functions of one argument is not that it says that something is such a function. Rather, the reason is that ' $\varepsilon(\varphi(\varepsilon)$ ' takes first-level functions of one argument as arguments, and what it says can be anything that is true of all such functions, such

\footnotetext{
${ }^{19}$ Since Frege does not use his technical notion of Bedeutung, we should not put too much theoretical weight on this statement. I say 'what we want to say' rather than 'what we mean' to preempt this.

${ }^{20}$ Compare: "The three words 'the concept 'horse"' do designate an object, but on that very account they do not designate a concept" (CP, 184).

${ }^{21}$ See also (Wells, 1968, 400) (Hugly, 1973, 229) (Geach, 1976, 57-58) (Ricketts, 2010, 182) (Hale \& Wright, 2012, 104) (Jolley, 2015, 8) (Jones, 2016, §5). As Diamond puts it: “The distinctions embodied in the concept-script are not what any thought can be about" (Diamond, 1991, 141).
} 
as ' $\varphi(0)=\varphi(0)$ ' or ' $(\forall x)(\varphi(x) \vee \neg \varphi(x))$ '.22 It is the logical hierarchy itself, as it is conceived by Frege, that makes it possible for a Begriffsschrift term to have a meaning such that it subsumes all first-level functions in the way ' $c ́ \varphi(\varepsilon)$ ' does. What does the work, is not primarily the meaning of ' $\varepsilon \varphi(\varepsilon)$ ', but the logical hierarchy in which, we could say, that meaning has its life. With regard to the logical categories, meaning comes too late. If we look at the Fregean realm of meanings and try to find a meaning that fits Frege's contrastive use of the logical category terms, we will see that no suitable meaning can be found. In this way, a logical category is not, for Frege, a highest genus, a maximally general concept. In this way, as well, logical categories differ fundamentally from a primitive notion such as identity, which can be captured by a Begriffsschrift term (i.e. the identitysign), but which is primitive because it stands at the beginning of the chain of definitions. Logical categories, on the other hand, are primitive because no Begriffsschrift terms can have them as their meaning, since any term that would seem to do the trick would refer to a concept. ${ }^{23}$. Contrary to notions such as identity, Frege never introduces Begriffsschrift terms for the logical categories, as has been noted many times (Conant, 2002, 385) (Ricketts, 2010, 170, footnote 50) (Weiner, 2010, 59-60). When Frege calls the logical categories logically primitive, this means something importantly different from when he calls a notion such as identity logically primitive.

\section{Talking about signs}

${ }^{22}$ Thus, Dummett believes we can render 'concept' by 'something which everything either is or is not' (Dummett, 1981, 216-217). Compare also (Beaney, 1996, 200) (Sullivan, 2006, 102, endnote 8) (Noonan, 2006, 165).

${ }^{23}$ In this respect, logical category terms are similar to the notion of 'truth'. As Ricketts explains, "the proper conclusion to [Frege's regress argument against a correspondence theory of truth] is not that truth is a primitive property, but that truth is not a property at all" (Ricketts, 1986, 79). Similarly, the proper conclusion of Frege's reflections on the logical categories is not that they are primitive concepts, but that they are not concepts at all. 
In discussing ' $\varepsilon \varphi(\varepsilon)$ ', Frege does not focus so much on its sense or reference, but points out the structural features of the expression itself, as it functions in the Begriffsschrift notation: "Whatever we now put in place of ' $\varphi($ )', we always get a true proposition because we can only put in names of functions of the first level with one argument, for the argument place here is of the second kind" (PMC, 136). Frege's focus, both in his discussion of ' $\xi$ is an object' and ' $\varepsilon \varphi(\varepsilon)$ ', is not primarily on the content of these expressions, but rather on their different structural place in the Begriffsschrift notation. This, I believe, is also what Frege has in mind in the last sentence of the following crucial passage from the correspondence:

The difficulty in the proposition 'A function never takes the place of a subject' is only an apparent one, occasioned by the inexactness of the linguistic expression; for the words 'function' and 'concept' should [logically] ${ }^{24}$ speaking be rejected. They should be names of second-level functions; but they present themselves linguistically as names of first-level functions. It is therefore not surprising that we run into difficulties in using them. [...] If we want to express ourselves precisely, our only option is to talk about words or signs" (PMC, 141).

Frege again points to the difference between first-level subsumptions and second-level subsumptions, a difference that is blurred in ordinary language but which is strictly in place in the Begriffsschrift. As before, I do not read Frege as saying that we can straight up introduce a primitive second-level function to stand for the logical category of first-level functions of one argument. Rather, he is trying to instill in Russell a sense of how the notational structure of the Begriffsschrift - with its device of argument-places - works to allow us to overcome the deficient expressive capacities of ordinary language. For Frege, part of what it is to gain insight into the sharp

\footnotetext{
${ }^{24}$ I am correcting the translation, which renders 'logisch' as 'properly' and inserts the word 'logical' into the next sentence.
} 
distinctions between the logical categories is to gain insight into the different kinds of Begriffsschrift signs with their different argument-places, and how they interact as components of Begriffsschrift propositions, i.e. how they serve to complete each other's argument-places. ${ }^{25}$ This, I take it, is the sort of understanding that is articulated in 'talking about signs'. ${ }^{26}$

This shows that, for Frege, our grasp of the logical hierarchy cannot be severed from our grasp of the Begriffsschrift notation. Indeed, it is only once we fully come to master the Begriffsschrift that we come to grasp the logical category distinctions that Frege seeks to instill in us. ${ }^{27}$ Frege thinks that, if he could bring Russell to grasp how the Begriffsschrift notation works to perspicuously express thoughts, he could help Russell find his way into his conception of the logical hierarchy. In order for this to make sense, we must realize that, for Frege, grasping how the Begriffsschrift notation 'works' is not a matter of grasping a set of merely syntactical rules for constructing sequences of marks on paper. As has been noted by multiple scholars, there is no room in Frege's logic for the contemporary distinction between syntax and semantics. ${ }^{28}$ Frege's conception of a Begriffsschrift sign is not that of a merely syntactical unit governed by merely syntactical rules of combination which acquires meaning through the subsequent external imposition of a semantic interpretation. What we would now call 'syntax' and 'semantics' are always interwoven for Frege. That a Begriffsschrift sign is a function-name, for instance, is not a merely syntactical property of that sign, but is intrinsically connected to its being used so as to

\footnotetext{
${ }^{25}$ See, for instance, the discussions at (GGA, I, $\left.\S \S 23\right)$.

${ }^{26}$ The Grundgesetze is full of such talk about signs, including the very sentence Russell used in formulating his objection: "a function-name can never take the place of a proper name, because it will involve empty places” (GGA, I, §21). Note Frege's invocation of the device of argument-places.

${ }^{27}$ See e.g. (Conant, 2020, 449ff.) for a fuller discussion of this point than I can provide here.

${ }^{28}$ See (Goldfarb, 2001) for a canonical exposition, and (Conant, 2020, 340ff.) for a survey. I cannot rehearse those arguments here, so I take this point for granted.
} 
designate functions. Paying attention to the notation, for Frege, does not mean grasping a set of merely syntactical rules but grasping how it is used to express thoughts. It is this sort of focus on notation - one in which the outward form of the notation displays the logical character of the use - that Frege believes helps us to grasp the logical categories. That is why Frege is so adamant that a function-name must always come with suitable argument-places:

"An isolated function-letter without an argument-place is surely a complete aberration, just as an isolated function-sign like ' $\sin$ ' is an aberration. For what characterizes a function, in contrast to an object, is just this unsaturatedness, that it requires completion by an argument, and this must feature in the notation too" [my emphasis] (GGA, II, $\S 147$, footnote 2).

The crucial point for us is this: for Frege, a full grasp of the logical categories always takes place against the background of the Begriffsschrift notation. It is an illusion to think that, when Frege says things such as that "functions are fundamentally different from objects" (CP, 153), the understanding that is at issue in such elucidatory statements can be attained independently of a grasp of how the Begriffsschrift notation works to express thoughts. ${ }^{29}$ It is precisely this point, I will now argue, that can underpin a more principled Fregean reply to Russell's proposal.

${ }^{29}$ This brings up the vexed topic of Fregean elucidation. Here, I must restrict myself to the observation that I take what I have called 'talking about signs' - i.e. the activity of clarifying how the Begriffsschrift notation works through the employment of a specific sort of discourse that takes Begriffsschrift signs as its subject matter - to be one main aspect of Fregean elucidation. This aspect has been somewhat neglected in the literature, which tends to focus on statements such as 'No concept is an object', which are not about signs. At the same time, I would not wish to claim that Frege had a fully coherent conception of this elucidatory activity of 'talking about signs'. Moreover, as I indicate below, I take the difficulties that are surfacing here to form a central part of Wittgenstein's worries in the Tractatus. I investigate these matters further in (Vanrie, forthcoming). 


\section{Part III: Why did Frege reject the theory of types?}

Because Frege seemed to be presupposing his own conception of the logical hierarchy in assessing Russell's proposal for a different such conception, his reply appeared dogmatic. I now wish to argue that Frege's seeming dogmatism can be motivated if we take into account the role played by notation in Frege's conception of the logical categories.

\section{Russell and notation}

According to Russell, if Frege's sharp distinction between functions and objects obtains, this constitutes a (logical) fact that we must be able to state in a proposition. That is why it is such a problem for him that "this fact cannot be stated without contradiction" (PMC, 134). See also (PoM, §49, §52). Insofar as one's conception of the logical hierarchy does not admit of expression in factual statements, it is self-undermining and must be rejected. Thus, for Russell, articulating the theory of types is a matter of articulating the facts that obtain about the structure of the logical hierarchy. This is what he attempts to do in his letter to Frege, by distinguishing between objects, ranges of values of objects, ranges of values of ranges of values, etc, and stating the categorical differences between them (PMC, 144). Of course, there is a tension here, since such talk is selfundermining for precisely the same kinds of reasons that Russell advanced against Frege. As noted, this is why Russell will adjust his conception. For us, however, the crucial point is that, for Russell, one's grasp of the logical hierarchy goes through such factual statements. ${ }^{30}$

${ }^{30}$ At least in his correspondence with Frege and also, I would claim, in the Principles of Mathematics, where Russell is in the business of presenting factual statements about the logical hierarchy, involving the categories of terms, things, and concepts (PoM, §§47-48). 
Not so for Frege, who rejects Russell's demand for such factual statements articulating the logical hierarchy. One's grasp of the logical hierarchy essentially involves one's grasp of the structure of the Begriffsschrift notation, as explained above. For Frege, there is no such thing as having a conception of the logical hierarchy without, we could say, having the notation to back it up. Our grasp of the logical hierarchy proceeds - not through factual statements - but through a suitable notation system, in which the relevant distinctions are manifested in the structure of the signs themselves. ${ }^{31}$

For Frege, then, the theory of types cannot be severed from the task of developing a suitable notation system. Russell, however, shows no awareness of such a task. For him, notation is external to the logical hierarchy. ${ }^{32}$ Russell's attitude towards notation can be gleaned, for instance, from his statement that, with regards to the discipline of symbolic logic, "the word symbolic designates the subject by an accidental characteristic, for the employment of mathematical symbols, here as

\footnotetext{
${ }^{31}$ It is tempting to put the point in the following Tractarian terminology: the logical hierarchy is not such as to be 'said' by propositions, but is shown in the structure of the Begriffsschrift notation. (I am grateful to an anonymous referee for suggesting this way of putting the point). Readers who find echoes of such Tractarian insights in my presentation of Frege are not mistaken. At the same time, assessing the precise relation between Frege and Wittgenstein with respect to the issue at hand is a complex exercise - one that falls outside the scope of this paper. Here I can only state without argument some of the claims I would defend in a fuller treatment of the topic. First, Wittgenstein agrees with Frege that our grasp of logical category distinctions cannot be severed from our grasp of a notation in which those distinctions are brought to expression (and is not such as to be stateable in propositions). Second, Wittgenstein takes Frege's conception of a 'sign' and his concomitant idea of 'talking about signs' to be incoherent. Third, this incoherence is due to Frege's unwittingly equivocating between the Tractarian notions of 'sign' and 'symbol'. (This does not amount, however, to an introduction of the contemporary distinction between syntax and semantics). Fourth, removing this conflation makes room for a different conception of the activity of 'elucidation' - which is connected to, but not identifiable with, the Tractarian notion of 'showing' - that is no longer beholden to the rigid Fregean dichotomy between the scientific Begriffsschrift use of a sign to express a thought on the one hand, and its elucidatory use conceived as external to the Begriffsschrift on the other hand. It would take yet more work, moreover, to fully spell out the bearing of these points on contemporary debates on the Tractatus. I would argue that my account of Frege and my suggestions about the Tractatus align more closely with so-called resolute readings of the Tractatus than with alternative readings.

${ }^{32}$ Black, in criticizing Frege, also takes notational matters to amount to nothing more than "purely practical considerations" (Black, 1968, 237). As an anonymous referee pointed out, this can be related to Russell's epistemology of acquaintance. Without being able to go into further detail: Russell seems to work with the picture of a direct, unmediated by symbols, acquaintance with logical categories.
} 
elsewhere, is merely a theoretically irrelevant convenience" (PoM, §11). ${ }^{33}$ Such a statement is anathema to Frege. ${ }^{34}$ From Frege's point of view, this attitude can also be gleaned from Russell's sloppiness with regards to notation. In the very letter in which Russell presents his incipient version of the theory of types, he also talks about identity between two relations, writing this as ' $R=S$ ' (PMC, 144). For Frege, this is sloppy for at least two reasons. First, Russell does not provide his signs for relations with suitable argument-places. Second, identity is not a relation between relations, but between objects. True to form, Frege points out that "a relation between relations is of a different logical type from one between objects" (PMC, 146). Throughout the correspondence, Frege repeatedly attempts to set straight what appears to him as Russell's notational sloppiness. ${ }^{35}$

\section{Types and argument-places}

${ }^{33}$ As Kremer puts it: "'Logic' in Principles is essentially independent of any particular system of notation" (Kremer, 2006, 184).

${ }^{34}$ A natural objection is that Russell changed his views on the topic, since he and Whitehead developed their own notation system for Principia Mathematica. There as well, however, we read: "The symbolic form of the work has been forced upon us by necessity: without its help we should have been unable to perform the requisite reasoning. [...] No symbol has been introduced except on the ground of its practical utility for the immediate purposes of our reasoning" (PM, I, viii). Such passages bespeak an attitude toward notation that is still much more instrumentalist than anything Frege would allow. Moreover, the notation of Principia Mathematica does not satisfy Frege's demands, since the distinctions between logical categories are not manifested in structural differences between the signs (the vexed phenomenon of typical ambiguity).

${ }^{35}$ E.g. (PMC, 133, 160-161). Note that this does not simply concern 'superficial' sloppiness, but sloppiness that has philosophical import: when Russell proposes another solution to the paradox, Frege argues that, once we clean up Russell's notation, the paradox reappears (PMC, 161-162). I owe this point to Jean-Philippe Narboux. 
It will have seemed clear to Frege that he could not expect Russell to provide an adequate notational framework for the theory of types. Still, this need not have prevented him from developing one himself. I wish to argue, however, that Frege had good reasons to think that this could not be done. As I have repeatedly emphasized, the fundamental notational device for Frege was that of argument-places. We distinguish between different types of signs on the basis of their argument-places. What is crucial here, is that the marks ${ }^{36}$ used to indicate those argument-places (call them place-indicators) have no function except to mark the argument-places in question: they make no further self-standing contribution to the meaning of the whole. Moreover, they indicate the type of the argument-place in question solely through their structure as a mark. Beyond that structure, the choice of what place-indicator to use is purely conventional. As Frege puts it: "When in what follows an expression like 'the function $\Phi(\xi)$ ' is used, it is always to be borne in mind that ' $\xi$ ' contributes to the designation of the function only insofar as it marks its argument places, and that the nature of the function would be unchanged if any other sign were put for ' $\xi$ '” [my emphasis] (GGA, I, §1). Using different place-indicators with the same structure (e.g. ' $\zeta$ ' instead of ' $\xi$ ', or ' $\psi(\tau)$ ' instead of ‘ $\varphi(\varepsilon)$ ') can never reflect a logical difference.

If one were to adapt Frege's device of argument-places to Russell's proposal, this conception of the argument-places would have to be abandoned. One would not only have to indicate, for instance, that an argument-place is to be occupied by a proper name, but also by what type of proper name. The mere structure of the place-indicator would no longer suffice to indicate the logical type of an argument-place: different marks with the same structure will have to be used to indicate different types, so that it is no longer logically indifferent which mark is used. For Frege,

\footnotetext{
${ }^{36}$ I am using 'mark' instead of 'sign' because the latter is, strictly speaking, inappropriate given Frege's conception of signs as I set it out above. As the passage below reveals, Frege himself is not fully rigorous about this.
} 
however, this is deeply problematic. If the specific mark used to indicate the argument-place is not logically indifferent, this means that the place-indicator itself makes a self-standing logical contribution to the meaning of the expression as a whole (since replacing it with a different mark with the same structure can make a difference to the meaning of the whole), which generates at least three problems. First, given Frege's compositional conception of Bedeutung, the fact that the place-indicator makes a logical contribution to the meaning of the whole, entails that it itself must have a meaning. But it is entirely unclear how to make sense of that. ${ }^{37}$ Second, given that the placeindicator has a meaning, the meaning of the whole can no longer be regarded as unsaturated in Frege's sense: it already includes a saturating component. Third, a special problem arises for proper names. In Frege's Begriffsschrift, their logical type is indicated by their completeness - the absence of argument-places - so that there is nothing present in the proper name wherein differences between logical types of proper names could be inscribed. It is entirely unclear, then, how to notationally mark the logical type of a proper name in a way that would satisfy Frege's demands on a logically perspicuous notation. All of this shows that adapting Frege's Begriffsschrift notation to the theory of types would involve nothing less than a complete abandonment of what we could call Frege's notational technique. Frege cannot be blamed, then, for not seeing a way into this endeavor.

\section{Law of excluded middle}

We can now also revisit Frege's claim that the theory of types violates the law of excluded middle. Our discussion has revealed the deeper philosophical reasons why Frege was wedded to

\footnotetext{
${ }^{37}$ One could say that it 'indefinitely means' objects of the type in question, or something of the sort, but Frege argued against such conceptions throughout his career (CP, 140, 287-288, 306-307).
} 
his peculiar conception according to which any object can be meaningfully subsumed under any concept, as in the notorious case of 'Julius Caesar is a number' (GL, §56), or our case of 'the class of square roots of 2 is a square root of 2'. This is not an idiosyncrasy, but anchored in Frege's views of what it is to have a conception of the logical hierarchy, to have an account of the logical categories. For Frege, the impossibility of using his notational device of argument-places to mark purported logical distinctions between objects shows that logic makes no such distinctions. All objects must be logically on a par, which means that they can all be meaningfully subsumed under any concept, no matter how awkward the resulting statement may be from a psychological point of view. That is why Frege claims that the theory of types leads to violations of the law of excluded middle, notwithstanding the fact that it purports to regard the relevant subsumptions as illusory. As Frege sees it, Russell has done nothing to back up the claim that he, Frege, had succumbed to a logical confusion in his implementation of the law of excluded middle. What Russell would need is not a blank statement that there are different types of objects, but the development of an adequate notational framework that perspicuously presents what it is to think in accordance with the theory of types. When Russell says that his proposal is "analogous to your theory about functions of the first, second, etc. levels" (PMC, 144), this must have appeared confused to Frege, given the farreaching mismatch between Russell's proposal and Frege's Begriffsschrift notation. It is not that Frege dogmatically refuses to take seriously Russell's proposal. It is rather, we could say, that Frege's demands for the seriousness of such a proposal have not been met, and that Russell shows little awareness of the need to meet them.

For Frege, what it is to subsume an object under a concept, the very nature of subsumption, is revealed, not in factual statements, but through an adequate logical notation, and Russell has not provided one. Similarly for Frege's claim that "identity is a relation given in so determinate a way 
that it is inconceivable that different kinds of it could occur" (GGA, II, 254). The determinate way in which it is given is precisely through its being expressed in the Begriffsschrift notation by a firstorder relation expression with two argument places. For Frege, the nature of identity as a first-order relation and the notational framework of the Begriffsschrift wherein that nature is brought to expression are inextricably bound together, and this framework does not allow for different kinds of identity.

I hope to have shown that there was, from Frege's own point of view, no option but to reject the theory of types. No matter how desperate Frege must have been for a solution, he had to continue searching for another way to circumvent the paradox - a search that, we know, would prove to be in vain, and would lead him to abandon his logicism. What he never abandoned, however, was the Begriffsschrift notation itself. Throughout his career, Frege remained absolutely convinced that he had succeeded - with the Begriffsschrift - in bringing to expression the structure of the logical hierarchy as it governs all thought.

\section{Acknowledgments}

This paper is deeply indebted to numerous conversations with Jim Conant. I am grateful to Michael Beaney, Juliet Floyd, Florian Ganzinger, Jonathan Gombin, Adrian Moore, Stephen Mulhall, Jean-Philippe Narboux, Gilad Nir, Thomas Pendlebury, Maria van der Schaar, and Maarten Van Dyck for helpful discussions. Earlier versions of this paper were presented at the second Göttingen/Chicago/Leipzig Graduate Student Conference in 2018, at the second TiLPS History of Analytic Philosophy Workshop in 2018, at Michael Beaney's Research Colloquium at the Humboldt University in Berlin in 2018, and at the $8^{\text {th }}$ annual SSHAP meeting in 2019. I am 
grateful to all participants for their helpful comments. I am also grateful to the referees of BJHP and of the BSHP Graduate Essay Prize for their helpful comments.

\section{References}

Beaney, M. (1996). Frege: Making Sense. London: Duckworth.

Black, M. (1968). Frege on Functions. In E. D. Klemke (Ed.), Essays on Frege (pp. 223-248). Chicago: University of Illinois Press.

Conant, J. (2002). The Method of the Tractatus. In E. H. Reck (Ed.), From Frege to Wittgenstein (pp. 374-462). Oxford: Oxford University Press.

Conant, J. (2020). Replies. In S. Miguens (Ed.), The Logical Alien (pp. 321-1028). Cambridge, Massachusetts: Harvard University Press.

Diamond, C. (1991). The Realistic Spirit. Cambridge, Massachusetts \& London: MIT Press.

Dummett, M. (1981). Frege: Philosophy of Language (2 ed.). London: Duckworth.

[GL] Frege, G. (1968 [1884]). The Foundations of Arithmetic (J. L. Austin, Trans.). Oxford: Basil Blackwell.

[PW] Frege, G. (1979). Posthumous Writings (P. Long \& R. White, Trans. H. Hermes, F. Kambartel, \& F. Kaulbach Eds.). Oxford: Basil Blackwell.

[PMC] Frege, G. (1980). Philosophical and Mathematical Correspondence (H. Kaal, Trans. G. Gabriel, H. Hermes, F. Kambartel, C. Thiel, A. Veraart, \& B. McGuinness Eds.). Chicago: The University of Chicago Press.

[CP] Frege, G. (1984). Collected Papers on Mathematics, Logic, and Philosophy (M. Black, V. H. Dudman, P. Geach, H. Kaal, E.-H. W. Kluge, B. F. McGuinness, \& R. H. Stoothoff, Trans. B. McGuinness Ed.). New York: Basil Blackwell.

[GGA] Frege, G. (2013 [1893/1903]). Basic Laws of Arithmetic (P. A. Ebert, M. Rossberg, \& C. Wright, Trans. P. A. Ebert, M. Rossberg, \& C. Wright Eds.). Oxford: Oxford University Press.

Geach, P. (1976). Saying and Showing in Frege and Wittgenstein. In J. Hintikka (Ed.), Essays in Honor of G. H. von Wright (pp. 54-70).

Goldfarb, W. (2001). Frege's conception of logic. In J. Floyd \& S. Shieh (Eds.), Future Pasts (pp. 25-42). Oxford: Oxford University Press. 
Hale, B., \& Wright, C. (2012). Horse Sense. The Journal of Philosophy, 109(1/2), 85-131.

Hugly, P. (1973). Ineffability in Frege's logic. Philosophical Studies, 24(4), 227-244.

Jolley, K. D. (2007). The concept 'horse' paradox and wittgensteinian conceptual investigations. London and New York: Routledge.

Jones, N. K. (2016). A Higher-Order Solution to the Problem of the Concept Horse. Ergo, 3(6), $132-166$.

Klement, K. C. (2004). Putting Form Before Function: Logical Grammar in Frege, Russell, and Wittgenstein. Philosopher's Imprint, 4(2), 1-47.

Kremer, M. (2006). Logicist responses to Kant: (early) Frege and (early) Russell. Philosophical Topics, 34, 163-188.

Landini, G. (1998). Russell's Hidden Substitutional Theory. Oxford: Oxford University Press.

Macbeth, D. (2005). Frege's Logic. Cambridge, Massachusetts: Harvard University Press.

Noonan, H. (2006). The Concept Horse. In P. F. Strawson \& A. Chakrabarti (Eds.), Universals, Concepts and Qualities: New Essays on the Meaning of Predicates (pp. 155-176). Burlington, VT: Ashgate.

Ricketts, T. (2010). Concepts, objects and the Context Principle. In M. Potter \& T. Ricketts (Eds.), The Cambridge Companion to Frege. Cambridge: Cambridge University Press.

Ricketts, T. G. (1986). Objectivity and Objecthood: Frege's Metaphysics of Judgment. In L. Haaparanta \& J. Hintikka (Eds.), Frege Synthesized (pp. 65-96). Dordrecht: D. Reidel Publishing Company.

[PoM] Russell, B. (2010 [1903]). Principles of Mathematics. London and New York: Routledge.

Sullivan, P. (2006). Metaperspectives and internalism in Frege. In M. Beaney \& E. H. Reck (Eds.), Gottlob Frege: Critical Assessments of Leading Philosophers (Vol. 2, pp. 85-105). London: Routledge.

Taschek, W. W. (2008). Truth, Assertion, and the Horizontal: Frege on 'The Essence of Logic'. Mind, 117, 375-401.

Van Heijenoort, J. (1967). Logic as Calculus and Logic as Language. Synthese, 17(3), 324-330.

Vanrie, W. "Signs and Elucidation in Frege." (Unpublished manuscript).

Weiner, J. (2010). Understanding Frege's Project. In M. Potter \& T. Ricketts (Eds.), The Cambridge Companion to Frege (pp. 32-62). Cambridge: Cambridge University Press. 
Wells, R. S. (1968). Is Frege's concept of a function valid? In E. D. Klemke (Ed.), Essays on Frege (pp. 391-406). Chicago: University of Illinois Press.

[PM] Whitehead, A. N., \& Russell, B. (2009 [1910, 1912, 1913]). Principia Mathematica: Merchant Books. 